\title{
UN PRESENTE CONTINUO SIEMPRE OLVIDADO: LAS MUJERES, LA SALUD Y EL CUIDADO. EL CASO DE ISABEL SENDALES
}

\author{
A FORGOTTEN CONTINUOUS PRESENT: WOMEN, HEALTH AND CARE. \\ ISABEL SENDALES' CASE
}

María Teresa Arias

Universidad Complutense de Madrid

\section{RESUMEN:}

Estudiar e investigar sobre la Historia de la medicina es una labor bastante compleja. Isabel Sendales fue la primera enfermera española, pues fue reconocida por Carlos IV. A pesar de que tenemos escasa información sobre Isabel, pero se sabe que dedicó su vida a cuidar y preservar la vida de muchos otros y desarrollar así una gran labor sanitaria y social.

\section{Palabras claves:}

Salud Isabel Sendales, cuidado.

\section{Abstract:}

Studying and researching about medical History is a very hard work. Isabel Sendales was the first Spanish nurse, since she was renowned by Charles IV. Despite the fact that we have barely information about her, but we know that devoted her whole life to take care and preserve the lives of many people and to develop a great sanitary and social labour.

\section{KEY WORD:}

Health, Isabel Sendales, care. 
Descubrir el mundo de la salud y del cuidado resulta una tarea compleja si lo que pretendemos ver en él son las manos femeninas. En primer lugar, por el silencio de las fuentes y, en segundo lugar, por su extensión en el tiempo, cuestiones que han requerido el acercamiento de especialistas cualificados capaces de generar una bibliografía rigurosa y precisa, aunque aún quede mucho por hacer.

Otro de los problemas a los que hay que enfrentarse al tratar este tema es el del propio concepto. Hasta época reciente la salud era vista como la carencia de enfermedad, y esta se ligaba a un sinnúmero de especulaciones y procesos oscuros a los que se pretendía dar sentido a través de la magia, la religión y una ciencia llena de tópicos y tabúes aún poco desarrollada. En la actualidad entendemos por salud algo bien distinto que abarca no solo el bienestar físico, sino también el mental y social, tal y como ha definido la OMS. En España, la Real Academia ha recogiendo tales ideas y otorga al concepto salud esa nueva dimensión y aún algo más cuando establece que es el conjunto de lo necesario para vivir bien; el disfrute de una vida holgada o abastecida de cuanto conduce a pasarlo bien y con tranquilidad y el estado de la persona en el que se le hace sensible el buen funcionamiento de su actividad somática y psíquica. En definitiva, un estado saludable no se concibe si el sujeto no es consciente de ello aunque, teóricamente, posea lo necesario para disfrutar del citado bienestar. Con independencia de estas cuestiones, lo que sí parece obvio es que sin cuidado no puede existir salud, exigencia que se ve acrecentada cuando es necesario recuperarla. Parece pues imprescindible conocer, cuando se realiza un análisis histórico de este complejo mundo, qué entiende por salud el grupo social examinado, qué medios utiliza y a quiénes se otorga su vigilancia y cuidado.

Si nos preguntamos desde cuándo puede computarse el cuidado entre los seres humanos y quiénes fueron los responsables del mismo, nos percatamos de que todo ello es algo que se pierde en la nebulosa del pasado. Investigaciones iniciales condujeron al grupo de los Neanderthales, cuyos individuos se ocuparon no solo de dar sepultura a los muertos, sino de cuidar y proteger a los ancianos, enfermos y discapacitados, dado que se ha constatado que entre ellos subsistieron seres muy limitados físicamente en un entorno, como sabemos, extremadamente riguroso. Sin embargo, los últimos yacimientos excavados en España nos hablan de que al menos la función del cuidado ya era ejercida con anterioridad. Así lo declaraba Ana Gracia, paleoantropóloga de la UCM y primera autora de la investigación que recogió José Corbella en La Vanguardia el 31 de marzo de 2009, cuyas palabras fueron:

"Tenía una rara enfermedad llamada craniosinostosis en la que las suturas entre algunos huesos del cráneo se fusionan de manera prematura. En su caso, se cerró prematuramente la sutura entre el parietal y el occipital en el lado izquierdo de la prematuramente la sutura entre el parietal y el occipital en el lado izquierdo de la lo que indica que probablemente sufría retraso mental. En la cavidad del ojo se ha detectado una anomalía llamada cribra orbitaria que indica que sufría alguna enfermedad de la sangre... Pese a su fealdad, su mala salud y su probable retraso mental, el volumen de su cerebro era de $1.200 \mathrm{~cm} 3$-aproximadamente igual al de un adulto actual-, lo que indica que cuando murió ya no era una niña pequeña".

Los estudios que habían verificado esta anomalía se apoyaban en el cráneo 14 correspondiente a una hembra de la especie Heidelbergensis (datada hace medio millón de años), a la que se bautizó como Benjamina, denominación más amable que el frío tecnicismo indicado anteriormente, y que falleció con una edad aproximada de diez años.

Tanto en el caso Neanderthal, como en el de sus antecesores de Atapuerca, nos es imposible saber qué pensaban estos individuos sobre el motivo de la enfermedad, lesiones, deformidades o heridas. Tampoco nos es dado conocer qué clase de cuidado practicaban y quien o quienes ejercían la tarea del cuidado: si eran jóvenes o adultos, hembras o machos, o si lo llevaban a cabo conjuntamente todos los miembros del grupo, dependiendo de las circunstancias y las situaciones. Este cúmulo de conjeturas, que hoy nos parecen tan verosímiles, no lo eran tanto hace apenas unos cuantos decenios ya que al igual que la Historia, quienes interpretaban la Prehistoria eran exclusivamente varones que plasmaron en los textos unas ideas patriarcales que adjudicaban, desde el inicio de los tiempos, ciertas tareas a las hembras de la especie, en la creencia de que se hallaban divididas por sexo las ocupaciones de la supervivencia. Sin embargo, en la actualidad, damos por sentado nuestro desconocimiento sobre cuándo, cómo y por qué tuvo lugar tal dicotomía social ya que solo existen especulaciones difíciles de corroborar por falta de testimonios concluyentes.

Pero, si abandonamos los tiempos ágrafos y nos centramos en aquellos que podemos documentar con textos u otras fuentes, descubriremos que, durante un período que llega casi hasta la Edad Contemporánea, en nuestro mundo occidental, y que aún pervive en otras zonas del planeta menos privilegiadas, salud y enfermedad han sido concebidos como los polos opuestos de una fina línea que podía cambiar de dirección, en un momento dado, al arbitrio de dioses, demonios o determinados comportamientos humanos. Es decir, que únicamente poderes superiores, de impenetrables designios, disponían quien debía estar sano y quien enfermo. La enfermedad, bajo este oscuro prisma, era vista como el resultado de caprichos insondables, castigo por acciones malvadas, o prueba para verificar la virtud de quien la padecía.

En este contexto, el cuidado de los enfermos no pasaba de ser un remedio para aliviar el dolor, pues la posibilidad de recuperación de la salud se enmarcaba dentro de un complejísimo mundo de valores, esquemas mentales diferentes a los nuestros y posibilidades científicas y técnicas que variaban según la idiosincrasia de los pueblos y sus perspectivas socio-culturales y espirituales. Durante todo este largo período de 
la existencia humana, y superándolo en este caso hasta el presente, las encargadas del primer nivel de cuidado de la salud fueron las mujeres. Y lo hicieron como parte de sus tareas asignadas en razón del sistema sexo-género, ya establecido. Fuera del hogar, en un segundo nivel, el cuidado de enfermos y heridos estuvo en manos de quienes ejercían el sacerdocio, la magia y el curanderismo, junto a otros individuos cuyos conocimientos científicos eran harto primarios e impredecibles, en un principio, y que fueron adquiriendo peso específico con el paso del tiempo. En realidad, un conjunto variadísimo de hombres y mujeres considerados capaces para tal actividad, bien como intermediaros de las divinidades, bien por ser considerados poseedores de capacidades sobrenaturales para intervenir sobre la naturaleza, o bien por hallarse en posesión de unos conocimientos médicos desconocidos para el resto de las gentes.

Sin embargo, aunque muchas mujeres estuvieron ligadas a la sanación fuera de recinto de su hogar, y aunque en él siguieran ejerciendo un magisterio indiscutible, una vez que se atribuyó la enfermedad a procesos naturales sobre los que se podía intervenir por medio de la ciencia, se consideró que únicamente los varones estaban capacitados para los estudios médicos y para ejercitar tal profesión.

En definitiva, existen desde que tenemos memoria, dos campos bien diferenciados en cuanto al cuidado de la salud; dos campos que irán aumentando paulatinamente su distancia de prestigio y reconocimiento social y acabará por excluir a las mujeres de la curación experimental y científica, tal y como afirma Carmen Caballero:

"Históricamente las mujeres se han encargado de las relaciones de creación y recreación de la vida humana: ellas crean y mantienen la relación. Sin embargo el valor de esta obra ha sido minimizado por el patriarcado, que la ha ignorado. Por ello no se ha recogido por escrito y, cuando se ha recogido, la retórica del discurso se ha encargado de borrar las huellas de la originalidad de hacer de las mujeres".

Las mujeres han venido cuidando el cuerpo de los miembros de la familia y con especial dedicación el de niños, ancianos, enfermos y heridos. Cuidar el cuerpo es el arte de cuidar la vida y en este arte tan importante han derrochado ingenio las mujeres aprendiendo unas de otras, generación tras generación. Aprendían de sus madres o de otras mujeres a preparara y administrar los más diversos remedios, en todas las formas posibles: tisanas, ungüentos, aceites, sahumerios, emplastes... dirigidos contra las más variadas dolencias: enfriamientos, tos, eccemas, diarreas, fiebres, extreñimiento, dolores de cabeza o de otras partes del cuerpo, retenciones de orina, etc., del mismo modo que se formaban para saber tejer, coser, lavar, guisar, administrar los recursos familiares, ya fuesen pocos o muchos, vigilar, educar,... En esta cuestión parecen estar de acuerdo todas las investigaciones consultadas, como muestran los siguientes ejemplos:
"Pero la mayoria de los enfermos eran atendidos en sus casas, siendo las mujeres las que los cuidaban, asumiendo así el papel de enfermeras... Para preservar a la familia de males, las mujeres debian convertirse en cuidadoras... debieron de aprender a satisfacer lo que hoy llamamos necesidades básicas y transmitir a sus hijas los mismos conocimientos que ellas ha llevasen a cabo el mismo cometido..".

Camel Ferragud ha utilizado documentos de aplicación para poner de manifiesto la gran cantidad de remedios caseros que utilizaban las mujeres para cuidar las enfermedades de sus familiares: “Una mujer de un campesino podía disponer de una gama suficientes y variados recursos como para asistir a aquellos que con ella convivían". Por su parte Cristina Segura señala:

"La atención en los partos y el cuidado de las enfermedades de todo tipo eran conocimientos tradicionales que las mujeres poseían y que se transmitían de madres a hijas... Estos conocimientos médicos, aunque no reconocidos como medicina, eran saberes empiricos que solo poseian las mujeres y entre ellas compartian. En algunos casos estos conocimientos las puso en peligro de ser acusadas de brujas. Las hierbas, determinados alimentos, algunos cuidados especiales, etc., eran los medios que usaban para la ayuda en las enfermedades. Nada de ello estaba escrito, todo era transmisión oral entre mujeres".

Margaret Wade afirma:

"La mujer que dirigía una casa, fuera cual fuese su tamaña o importancia, parece haber sido responsable de la salud de los que entraban dentro de su esfera de influencia... La participación de la mujer corriente en el arte de curar comenzó con la aplicacion de primeros auxilios a los que las rodeaban. Formaba parte aceptada de la educación de una dama noble saber tratar las heridas, los huesos rotos o dislocados y los golpes graves con que los hombres de su casa podían regresar de las guerras, torneos o enérgicas cacerías. Los romanos indican la conveniencia de que las mujeres fueran expertas en vendajes, ungüentos y limpieza de heridas, al haber aprendido estas artes como parte de su educación".

Y la profesora en historia de la medicina Gianna Pomata asegura que:

"A pesar de su papel marginal en la práctica profesional, las mujeres estuvieron siempre al lado de los lechos de la gente enferma... En realidad ellas eran cuidadoras y no solo sanadoras. Las mujeres y los barberos presidieron las tareas manuales de cuidado del cuerpo enfermo que los sanitarios de categorías superiores desdeñaron por degradantes. Unas y otros 'curaban el cuerpo con el cuerpo' y por consiguiente estaban en la base de la pirámide que estructuraba las artes sanitarias en el antiguo régimen".

De igual modo, podría acercarme a las fuentes directas donde pueden rastrearse testimonios de lo más sugerentes, como el que nos transmite Homero: 
"Entonces Helena echó en el vino del que bebían un fármaco contra el llanto y la cólera, que hacía olvidar todos los males... Tan excelentes y bien elaborados fármacos tenía en su poder la hija de Zeus, que le había dado la egipcia Polidamna, esposa de Ton, cuya feraz tierra produce muchisimos, los cuales al ser mezclados, unos resultan saludables y otros nocivos".

Más cercano a nosotros se encuentra el texto de La Celestina, que nos descubre el arte de curar de la protagonista; en realidad, un sugerente mundo en que se solapan saberes medio empíricos, medio hechiceriles cuando ya alboreaba el Renacimiento:

“...Tiene esta buena dueña al cabo de la cibdad, allá cerca de las tenerías, en la cuesta del río, una casa apartada, medio cayda, poco compuesta y menos abastada. Ella tenia seys officios, conviene (a) saber: labrandera, perfumera, maestra de hazer afeytes y de hazer virgos, alcahueta y un poquito hechizera. Era el primer officio cobertura de los otros,... Hazíase física de niños... Y en su casa hazía perfumes, falsava estoraques, menjuy, ánimes, ámbar, algalia, polvillos, almizcles, mosquetes Tenía una cámara llena de alambiques, de redomillas, de barrilejos de barro, de vidrio, de arambre de estaño, hechas de mil faciones; hazia solimán, afeyte cosido, argentadas, bujelladas, crillo, llanillas, unturillas, lustres, lucentones, clarido, (asimietes, alvalines y otras aguas de rostro, de rassuras de gamones, de mosto, destillados y açucarados. Adelgasava los cueros con çumos de limones, con turvino, con tuétano de corço y de garça y otras confaciones. Sacaba aguas para oler, de rosas, de azaar de jasmín, de trébol, de madreselvia y clavellinas, mosquatadas y almizcladas, polvorizadas con vino. Hazía lexías para enruviar, de carrasca, de centeno, de maurrubios, con salitre, con alumbre y millifolia y otras diversas cosas. Y los untes y mantecas que tenía, es fastío de dezir... Aparejos para baños, esto es una maravilla; de las yervas y rayzes que tenía en el techo de su casa colgadas... Esto de los virgos, unos hazía de bexiga y otros curava de punto... Y en otro apartado tenía para remediar amores y para se querer bien: tenía huessos de coraçon de ciervo, lengua de vibora... y otras mil cosas. Venían a ella muchos hombres y mujeres, a unos demandava el pan do mordíon, a otros, de su ropa; a otros, de sus cabes, y a unos de vibellos, a otros, pintava en la palna letras con açáfrán, a otros con bermellón, a otros dava unos coraçones de cera, llenos de agujas quebradas, y a otras cosas en barro y en plomo fechas, muy espantables a ver. Pintava figuras, dezía palabras en tierra...".

\section{O el de la lozana andaluza que sigue en esta línea:}

"Yo sé embalsamar... Sé quitar ahitos, sé para lombrizes, sé encantar (sanar, cura con ensalmos) la terciana, sé remedio para la cuartana y para el mal de la madre (útero). Sé cortar frenillos de bobos y no bobos, sé hacer que no duelan los riñones y sanar las renes, y sé medicar la natura de la mujer y la del hombre, sé sanar la sordera y sé envolver sueños, sé conocer en la frente la fisonomía, y la quiromancia en la mano, y prenosticar".

Son extremadamente clarificadores a nuestro intento los documentos artísticos ya que, muchas veces, aportan la información que no nos facilitan los textos, sobre todo aquellos que hacen referencia a escenas de la vida cotidiana que para los eruditos no se estima necesario describir. Así, es sumamente curiosa la serie de ilustraciones que ofrece la obra editada por Eduardo Acosta sobre la medicina griega y romana. En ella no se habla de las mujeres más que como pacientes, salvo en el caso de Helena, ya que los textos sobre los que trabaja este autor pertenecen a ilustres sabios griegos y romanos. Sin embargo, las sobredichas imágenes documentan la actividad sanadora y cuidadora de las mujeres dentro y fuera del hogar como se verá a continuación. Es seguro que un estudio minucioso del ingente repertorio artístico de que disponemos, sería fuente valiosa para acercarnos al mundo femenino de la sanación y el cuidado. Los ejemplos seleccionados son los siguientes:

Un joven enfermo vomita ayudado por una mujer (plato griego del Wagnere Museum de Wurzburg) Una escena similar se representa en otro plato griego existente en los museos Vaticanos. Podemos contemplar asimismo la tumba de una mujer medica procedente del siglo I d. C., aunque no se indica su ubicación. Y, finalmente, podemos observar, La escena de un parto en el que una comadrona y su asistenta ayudan a una mujer a dar a luz. Motivo que se encuentra en un bajorrelieve fechado en el siglo II d. C. y que corresponde al Museo de Ostia en Roma. Una representación en la que solo podemos encontrar mujeres y que podríamos multiplicar "ad infinitum", si reparamos en las representaciones del nacimiento de Jesús, de María, de San Juan o de cualquier santo, a lo largo de toda la historia de la pintura.

En realidad, y como se viene indicando, cientos de testimonios nos hablan de esa maravillosa obra desempeñada por las mujeres a lo largo de la Historia. Su presencia invisible nos ha dotados a todas y todos de visibilidad, por lo que es justo reconocer que su labor de cuidado, siempre insustituible, lo fue mucho más en los tiempos en que la ignorancia era el terreno abonado de la ciencia y donde no existían instituciones $\mathrm{u}$ organismos que se ocuparan socialmente de los necesitados y de los enfermos.

Ineludible fue, por otro lado, la atención prestada por las mujeres cuando se trataba de vigilar y cuidar otros cuerpos de mujeres. Ello debido a que el patriarcado volcó sobre el cuerpo femenino una serie de prejuicios y tabúes que obligaba a la atención de unas mujeres por otras y, por ende, durante muchísimo tiempo, condujo a un absoluto desconocimiento del cuerpo femenino y sus dolencias por parte de quienes terminaron por desempeñar la función social del cuidado sanitario: los varones. Tales consignas obligaron a buen número de mujeres a seguir practicando su ciencia en el exterior del hogar, actuando sobre las enfermedades específicas femeninas, ayudando a las parturientas, o examinando y emitiendo dictámenes en procesos judiciales tales como violaciones, embarazos, frigidez, etc.

Hubo, igualmente, quienes por su especial situación en el ámbito social, o por su grado superior de instrucción, intentaron aliviar el dolor de sus dependientes y próximos como recogen singulares testimonios. Tal fue el caso concreto de Lady Mildmay, dama inglesa del siglo XVII que, según ella misma relata había recibido los 
conocimientos de su madre y los transmitió por escrito a sus hijas. De su actividad da cuenta un contemporáneo admirado de su labor y, sobre todo, de que respetara la autoridad de los varones de acreditado conocimiento:

"Yo no rechazaría a todas las mujeres adictas a la cirugía sin excepción, porque he conocido a algunas que por su valía y sabiduría pueden equiparse con los grandes hombres; mujeres que prestaban el debido cuidado a la realización de sus curas y las terminaban con verdadera caridad: como la cabal, religiosa y virtuosa dama Lady Mildmay de Apethorpe, en el condado de Northampton, que poseía por sí misma un buen juicio en muchas cosas; $y$, no obstante, cuando las gentes pobres iban a su casa en busca de ayuda (puesto que sembró su práctica entre estas personas), si eran casos de física, buscaba la aprobación de un médico; si se trataba de problemas quirúrgicos, buscaba la ayuda de un cirujano, y si se trataba de problemas oculares la mía propia".

Como se puedeobservar, se conjuganen estetexto dos delas actividades desarrolladas por las mujeres en torno al cuidado de la enfermedad: la desempeñada en el recinto del hogar, que no precisaba de supervisión y en el que eran autoridad indiscutida, y la desarrollada de puertas afuera de su casa, en la que las mujeres debían mostrar respeto por los conocimientos que ya les estaban vedados por hallarse en poder de los varones. Lo cierto es que bien por sabiduría y pericia, bien por vocación o incluso por necesidad u obligación, muchas mujeres, con la aquiescencia o la prohibición de las autoridades, siguieron durante muchísimo tiempo cuidando la salud a personas ajenas a su hogar. Tales mujeres actuaban tanto en el medio rural como en el incipientemente urbano. La mayoría ejercían la sanación de buena fe, poniendo sus conocimientos (mejores o peores), al servicio de quienes las requerían porque confiaban en ellas, porque no existía nadie más cualificado o porque contribuían con sus actos a tapar los vacíos de quienes no disponían de medios para pagar los elevados salarios de los galenos.

Algunas, como hemos visto, supieron sortear las prohibiciones de ejercitar actividades sanadoras fuera del hogar. Prohibiciones que llevaban aparejadas fuertes sanciones, caso de infringirlas. Solo tenemos que recordar el destino de tantas curanderas acusadas de brujería que pagaron con su vida su atrevimiento, o aquel que hubieron de sortear muchísimas otras, enfrentándose a durísimos juicios de los que nunca salían vencedoras a pesar de los innumerables testimonios a su favor. Tal fue el caso concreto de Jacoba Felicié, a quien enjuició el Protomedicato de París y que fue sancionada a pesar de ser reconocida como extremadamente capaz en el ejercicio de la medicina. Es cierto que hubo etapas históricas o espacios geográficos más permisivos y en ellos las mujeres ejercieron la sanación desde las más altas cimas del saber y el reconocimiento, como sucedió con las médicas de Salerno, o con aquellas que la practicaron junto a sus maridos o hijos o, una vez viudas, lo hicieron en sustitución de aquel. Con todo, fueron períodos muy limitados, o situaciones muy concretas que acabaron por desaparecer, ahogados por las pretensiones de quienes lograron realizarlo con todos los parabienes sociales.

Efectivamente, cualquier veleidad femenina de ocupar posiciones relevantes en el campo de la medicina quedó cercenada en la baja Edad Media, cuando la práctica médica se organizó institucionalmente y como se ha señalado los estudios quedaron insertos en las universidades donde las mujeres no tenían cabida. En el esquema mental de la época se hallaban demasiados obstáculos que sortear además de esta formación académica indispensable. En primer lugar, las mujeres carecían del necesario reconocimiento de autoridad para formarse y efectuar dictámenes (eran consideradas incapaces de discernimiento racional e inteligencia superior). En segundo lugar, las mujeres carecían del reconocimiento de independencia, no solo de voluntad, sino económica, con respecto a padre, marido, hermanos, y el entorno social y, en tercer lugar, y no menos poderoso, el ejercicio de la medicina implicaba la necesidad de moverse libremente entre los hombres, conocer y reconocer sus cuerpos. Únicamente las “malas mujeres" podían realizar esto último. Únicamente ellas podían atreverse/exponerse a un contacto indecente e inmoral. El resto de las mujeres, las consideradas castas, debían eludir todo acercamiento a un mundo que podía perderlas por la fragilidad de su carne (concupiscente por naturaleza), y por la procacidad de los hombres.

En este contexto se enmarca un tercer nivel de cuidado ejercido por las mujeres fuera del hogar y alejado del cerrado círculo de médicos y cirujanos: el de la enfermería, aunque tal palabra no tuviera hasta hace poco el sentido que hoy le otorgamos. Consistía, esencialmente, en vigilar y atender al enfermo en sus necesidades más básicas: aseo, consuelo, alimentación, administración de hierbas, o preparados, etc.

Es difícil realizar un estudio exhaustivo de la evolución de este tipo de cuidado en unas pocas líneas, por lo que, como con los dos niveles de cuidado anteriores, ya tratados, solo se pretende dar una visión general del mismo. De él podemos afirmar, por los motivos que se han ido señalando, que el prestigio y el reconocimiento de su labor dependieron de la condición de quienes lo realizasen y las motivaciones que les llevaban a ello. Nunca fueron vistas con los mismos ojos quienes lo acometieron por pura supervivencia, que quienes lo hicieron impulsadas por un ideal. Nunca sería mirada de igual modo una mujer desprestigiada por la edad, o considerada accesible sexualmente, que otra que no lo fuera; es decir, una laica y una religiosa. El sistema imponía a las mujeres el matrimonio y la reproducción. Las solteras eran mal vistas porque no habían cumplido con su misión en el mundo y las viudas que se permitían disponer de sí a su antojo tampoco lo eran. Otra cosa diferente eran las religiosas, que habían cumplido de alguna manera con su gestión al hacerse esposas de Cristo y adoptar como hijos a todos los seres humanos. 
Ciertamente, entre las primeras, habia algunas de dudosa moralidad para la mentalidad de un mundo que ha llegado desde la antigüedad a nuestros días. Las soldaderas, por ejemplo, que han acompañado a los ejércitos desde la antigüedad y ejercían labores sanitarias y de cuidado, estarían codificadas dentro de este grupo. Muchas de ellas eran prostitutas o estaban ligadas a hombres sin los debidos parabienes sociales, lo que las incluía en el saco de las "malas mujeres".

A ello hay que añadir las limitaciones y carencias no solo técnicas, sino materiales, la falta de higiene, el hacinamiento y la penuria general de los lugares donde se desenvolvió durante muchísimo tiempo este tipo de asistencia, pues no solo podemos pensar en la Edad Media, sino en la Edad Moderna y aún en la etapa Contemporánea, como denunciaron numerosas personas comprometidas socialmente. Veamos como ejemplo lo que dice acerca de las deplorables condiciones del viejo Hôtel Dieu de Paris, fundado en el año 1651, Gabriel Hanatoux:

\section{"Los enfermos, amontonados unos sobre otros, se acostaban, cuatro o seis en una misma cama, se contagiaban mutuamente y morían como moscas, convirtiendo el barrio que lo rodeaba en un foco de epidemias; la peste diezmaba regularmente a la población parisina"}

Una situación que aún perduraba un siglo más tarde, a decir de Georges Cuvier:

\section{"Las penas del infierno pueden superar apenas estos desdichados, aprisionados} unos contra otros, asfixiados, ardiendo sin poderse mover y respirar, a veces con uno o dos cadáveres entre ellos durante horas enteras".

Por todos estos motivos, no es de extrañar que se generase en dichos establecimientos un caldo de cultivo donde la ignorancia se volvía contra quienes estaban al pie del enfermo por unas míseras monedas y esto agriaba los caracteres de quienes desempeñaban tal labor. Las ancianas o poco agraciadas eran satirizadas o vejadas por los enfermos y familiares, y las jóvenes recibían proposiciones y hasta agresiones físicas y sexuales sin posibilidad de defenderse. Tal conjunto de situaciones incidía sobre un colectivo desacreditado en exceso hasta hace relativamente poco. De hecho, el cuidado enfermero laico carecía de prestigio, era considerado poco digno y para su ejercicio no se estimaba necesaria cualificación alguna: "porque el cuidado del ganado y de los enfermos de los hospitales lo realiza mejor el sexo femenino".

Nada parecido a la valoración que recibían aquellas que prestaban atención a los necesitados, inspiradas por el amor a Dios, o curaban a enfermos y heridos considerando que eran mediadoras de sus designios. Ellas lograron saltar las barreras de la imposibilidad y ser apreciadas y valoradas por su tarea, como ocurrió desde los primeros tiempos del cristianismo con las matronas romanas que fundaron establecimientos para el cuidado de enfermos a sus expensas y ellas mismas lo abordaron, las diaconisas, o las monjas de los numerosísimos monasterios medievales. Ahí están, para ejemplo de las miles de ellas que lo efectuaron, entre otras, la ya famosísima Hildegarda de Bingen, cuya medicina abarca el campo práctico y teórico llevado a cabo desde su monasterio de Rupetsberg y, posteriormente de Eibingen, o Catalina de Siena, que ejerció como terciaria en oposición abierta a los deseos y expectativas de su familia, o algunas otras menos conocidas como Santa Ubaldesca, monja pisana, del siglo XII que comenzó sus tareas del cuidado de enfermos a los quince años y durante cincuenta y cinco se entregó a ellos en el hospital de su ciudad perteneciente a la Orden de San Juan del Hospital.

No podemos dejar de recordar el importante movimiento beguino desarrollado en el norte y centro europeo, constituido por grupos de mujeres que se asociaban para sobrevivir, sin atarse a reglas ni superiores y que desempeñaron una gran labor en los hospitales y leproserías. No eran religiosas, pero sí mujeres piadosas que adquirieron gran estimación entre sus conciudadanos.

En general, durante toda la Edad Media y Moderna, muchas mujeres imbuidas por la ideología transmitida desde todos los ámbitos sociales, sintieron la necesidad de sortear la tan traída y llevada infirmitas sexus -literalmente enfermedad del sexo femenino, en referencia a su incapacidad, debilidad y miseria-, de la que eran portadoras como hijas de Eva, aplicándose al ejercicio de la caridad, la piedad, la dulzura y, ante todo, la honestidad, meta irrenunciable sobre todas las demás. Elemento fundamental en la forja de las cuidadoras religiosas fue la presentación de la Virgen María, corolario de la genealogía femenina, bajo numerosísimas advocaciones que hacían referencia a cualidades que debían imitar las mujeres y que me voy a permitir enunciar para que toméis conciencia de la fuerza ejercida sobre las mujeres con ello: Socorro, Consuelo y Remedio de los afligidos, Auxilio de los pobres, Salud de los enfermos, Madre de los Desamparados, Señora de todos los Dolores, de las Penas y de las Angustias, Madre Clemente y Misericordiosa, María de las Lágrimas, del Buen Fin, de la Esperanza, de la Piedad, de la Amargura, del Desconsuelo, De la Cinta, de la Leche, del Perdón... La literatura la mostrará cálida y acogedora para todos aquellos que le rindan tributo y mediadora diligente entre la divinidad y quien ha enfermado de cuerpo o de alma por el pecado. Es más, la Virgen aparecerá en la iconografía como “Hospital para los cuidados", tal y como sugieren las Cantigas de Santa María.

Seguir los pasos de las santas, las mártires y, en la medida de lo posible los de la Virgen, habría de convertirse en la meta de muchas mujeres. Entregadas a las buenas obras un buen número de ellas consiguió, en los monasterios y en los hospitales de caridad, su objetivo: tal vez, por qué no, alejarse de un matrimonio no apetecido, del dominio de los hombres, de las maternidades impuestas y, asimismo, despegarse del 
mundo y sus significados, incluso acariciar cierto grado de libertad o acercarse a un mayor nivel de formación... A algunas, incluso, esta dedicación las salvaba de caer en situaciones adversas tales como la mendicidad o la prostitución.

Sabemos que la mayoría de los centros dedicados al cuidado de los enfermos dependían de la iglesia y dado que los conocimientos médicos eran muy limitados y los recursos extremadamente escasos, su objetivo, más que curar a los dolientes, era procurarles alivio y consuelo por medio de una mejor dieta alimenticia, higiene, algunas medicinas y purgantes y, en algunos casos, la realización de sangrías si no existía cirujano-barbero.

Ya a finales del siglo XVI, entre otras organizaciones destinadas al cuidado de los enfermos, será de vital importancia la aparición y el desarrollo de las Hijas de la Caridad fundadas por Vicente de Paul y Luisa de Marillac. Institución que forjada sobre la base de mujeres incultas y sin fortuna, destinadas a auxiliar y aliviar la enfermedad, supo sortear estas premisas y convertirse en un hito trascendental en los hospitales de todo el mundo desde aquel siglo hasta el presente. Una fundación que insistiría en la formación continuada de quienes la componían (en materias generales y médicas), pues no solo se les enseñaba a leer y escribir sino que también se exigía que se preparasen para realizar aquellas técnicas específicas de su oficio, como sangrar aunque, por supuesto, dentro de los parámetros que permitía cada momento histórico. Una fundación sin la que no podría entenderse la aparición de la mujer que revolucionaria la enfermería civil: Florence Nightingale, formada en dicha institución. En ausencia de un cuerpo de enfermería civil reconocida y acreditada, fueron, especialmente, las Hijas de la Caridad las que contribuyeron a la salud de miles y miles de enfermos en los territorios católicos o de misión.

Desde luego, hasta el siglo XIX no puede hablarse de una enfermería laica de calidad, dado que, como se ha indicado, salvo las Hijas de la Caridad, que contaban con el respeto general de médicos y enfermos, las seglares que se dedicaban a la difícil tarea del cuidado por dinero, procedían de extracciones comprometidas y seguían siendo muy mal vistas, en especial, en los países protestantes en los que no existían religiosas dedicadas a los enfermos. Walker Keneth describe así tan trágico panorama:

"Medio fregonas, medio borrachas, han sido magistralmente descritas por Dickens... Para tener idea de adónde había llegado el cuidado de los enfermos en los hospitales, basta con leer el editorial de The Times, Londres, 15 de abril de 1857: 'Sermoneadas y reñidas por los limosneros y directores, menospreciadas por los pagadores, injuriadas por los cirujanos, tiranizadas por los enfermeros, cubiertas de oprobio por los propios enfermos, insultadas cuando son viejas o fea, trabtas de oprobio por los propios enfere con excesiva familiaridad cuando son de buen ver, seducidas si son jóvenes y bonitas... El salario era irrisorio. Una sola cuidaba de una sala con diecisiete camas y trabajaba desde las seis de la mañana hasta las siete de la tarde...".
De ahí que, precisamente, la reforma de la enfermería comenzase en Alemania, de manos del pastor protestante Teodor Fliedner, quien fundó la primera escuela de enfermeras, modelo para distintas escuelas de Alemania y otros países.

Un impulso posterior vendría de manos de la ya mencionada británica Florence Nihgtingale, vivamente interesada en el cuidado de los enfermos, pero que, como tantas otras, no contaba con el beneplácito de sus progenitores cargados por los prejuicios que se cernían sobre las mujeres dedicadas a esta tarea. No hubo nada que lograra disuadirla. A comienzos del año 1850 entró en contacto con las Hijas de la Caridad en su hospital de Alejandría (Egipto) y aprendió de ellas las primeras nociones de enfermería. Posteriormente, visitó la escuela Fliedner y cursó estudios en ella. Al estallar la guerra de Crimea no le faltó la fuerza y el arrojo para enfrentarse a todo y a todos e iniciar su cruzada particular denunciando la terrible situación en que se encontraban los enfermos ingleses, "mientras que Francia disponía de excelentes hermanas de la caridad que cuidaban de los heridos". Su tesón, firmeza de carácter y el convencimiento de que aquel empeño suyo era imprescindible le ayudaron a organizar la asistencia a los soldados ingleses. Una vez iniciado el proceso, de regreso a Inglaterra, fundó una escuela de enfermeras en el hospital de Santo Tomás. Otras personas seguirían su ejemplo y, pocos años después, resultado indirecto de su obra, en 1864, en Ginebra, Henri Dunant, fundaría la Cruz Roja Internacional.

España no quedaba fuera de este panorama internacional y, como el resto de los países, el siglo XIX finalizaría sin que existiese título oficial de enfermería, aunque ya en 1858, algunas mentes iluminadas habían hecho oír sus voces en cuanto a la conveniencia de crear escuelas donde se formara personal para el ejercicio de las tareas del cuidado. Unas tareas, cada vez más complejas y que iban requiriendo de regulada profesionalización. Pedro Felipe Monlau, catedrático de higiene de la Universidad de Madrid, gran humanista del XIX, escribió en el Monitor de la Salud de las Familias, un artículo titulado: "Arte de cuidar enfermos", en el que sugería dicha actuación.

Consecuente a su preocupación y a la de otras personas que pensaban como él se estableció la primera escuela de enfermeras llamada de Santa Isabel de Hungría, en 1896. Parece oportuno señalar que esta efervescencia en cuanto a la ocupación femenina de enfermería laica debe encuadrarse dentro de un esquema general y un debate muy confuso - difícil de precisar aquí por su misma complejidad y extensión temporal-, que desde antiguo venía buscando vías de solución. Las mujeres llevaban siglos intentando granjearse el respeto de los varones en cuanto a sus capacidades, parcelas de poder $\mathrm{y}$, sobre todo, de conocimiento. Desde la Edad Media, e incluso mucho antes, algunas privilegiadas -bien por su poder económico, bien por su instrucción-, y muchas de ellas insertas en los marcos religiosos, venían exigiendo, de palabra o de obra, espacios distintos a aquellos en los que se las había confinado; espacios donde desarrollarse 
intelectualmente, espacios, en fin, donde darse a sí mismas contenido como personas con independencia de la función biológica de la maternidad.

El siglo XX y nuestro actual siglo XXI han ido viendo crecer el merecido prestigio de las mujeres dedicadas al cuidado de los enfermos y heridos, prestigio que aumentó considerablemente con las exigencias de estudios superiores y por qué no decirlo, con la entrada de varones en el oficio.

Hasta aquí he intentado dar una visión general sobre la dedicación de las mujeres al cuidado del cuerpo ajeno, en general, y al cuidado del cuerpo carente de salud, en especial, así como el poco reconocimiento que en este, como tantos campos, se les ha otorgado, si comparamos sus esfuerzos en relación con el tiempo que llevan desempeñándolos. Dentro de esta falta de reconocimiento podemos citar el caso de Isabel Sendales, una absoluta desconocida para la mayoría de la gente. Isabel Sendales fue, sin embargo, la primera enfermera española, pues con dicho título quedó inscrita en el libro de la Historia y recibió por sus tareas sueldo de tal, concedido por Carlos IV.

Isabel, de quien se desconoce absolutamente todo salvo su nombre (pues ni siquiera en el apellido hay concordancia en las fuentes), dedicó una gran parte de su vida a cuidar la vida, a preservar la vida y a garantizar con su trabajo y su desvelo que unos niños, cuyo número aún no ha podido ser cuantificado de forma exacta y que se estima en torno a los cien, lograran portar sobre sus brazos el fluido que liberaría de la viruela a miles y miles de personas.

Su nombre salta a la historia cuando, de forma inesperada, es sumada a la Real Expedición Filantrópica de la Vacuna que dirigida por el coronel médico Francisco Javier Balmis se encaminó hacia las colonias hispanas (tanto americanas como Filipinas) para atajar la pandemia de viruelas, con un exiguo número de cuatro médicos, dos practicantes y cuatro enfermeros militares. La expedición cuyo desarrollo está perfectamente estudiado y delimitado discurrió por aquellos mundos en circunstancias no demasiados agradables, dadas las condiciones en que se tenía que viajar entonces y durante nada menos que siete largos años.

Como se ha indicado, se la nombra a propuesta del director de la expedición, el doctor Balmis y de Ignacio Carrillo, presidente del Hospital de la Caridad, con fecha 14 de octubre de 1803, en calidad de enfermera:

“Conformandose el Rey con la propuesta de Vm. y del Director de la expedición destinada a propagar en Yndias la inoculacion de la vacuna, permite S.M. que la Rectora de la Casa de Expósitos de esa Ciudad sea comprehendida en la misma expedición en la clase en Enfermera con el sueldo y aiuda de costa señalada á los Enfermeros, para que cuide durante la navegacion de la asistencia y aséo de los Niños, que haian de embarcarse, y cese la repugnancia, que se experimenta en algunos Padres de fiar sus hijos al cuidado de aquellos sin el alivio de una Muger de providad. Con esta fecha paso el aviso correspondiente al Ministerio de hacienda para que la Rectora reciva en esa Ciudad la aiuda que costa de tres mil rs. con destino á su havilitación, y para el abono en Yndias del sueldo de quinientos ps. annuales, contados desde el dia que embarque, y la mitad á su regreso, que debera ser de cuenta del Erario; y á Vm. lo participa de Rl. Ordenes para la inteligencia de la Junta de caridad, de que es Presidente y noticia de la Ynteresada".

La expedición salió del puerto de La Coruña en noviembre de 2003 y se dio por concluida en 2010 con la muerte del subinspector de la expedición don José Salvany que siguió actuando en Sudamérica hasta dicho momento. Isabel, es rememorada por el doctor Balmis, no muy dado a elogiar a nadie y si muy propenso a recibir todos los honores y colocarse todas las medallas, a decir de las fuentes. De ella dijo lo siguiente:

“La miserable Rectora que con el excesivo trabajo y rigor de los diferentes climas que hemos recorrido, perdió enteramente su salud, infatigable noche y día ha derramado todas las ternuras de la más sensible Madre sobre los 26 angelitos que tiene a su cuidado, del mismo modo que lo hizo desde La Coruña y en todos los viajes y los ha asistido enteramente en sus continuadas enfermedades".

Isabel, olvidada, como tantas otras, ha sido citada por algunos investigadores no solo como la primera enfermera española, sino como la primera enfermera internacional de la Historia. A pesar de los esfuerzos de las rigurosas investigaciones realizadas al hilo de la conmemoración del segundo centenario de la expedición, Isabel sigue siendo una mujer por descubrir. ¿Qué hubiese ocurrido si esta pionera hubiese sido inglesa, francesa o norteamericana? Probablemente se la habría dado mayor protagonismo, se le hubiesen erigido monumentos por toda la geografía nacional, su nombre habría bautizado calles en un sinnúmero de ciudades, se le hubiesen dedicado homenajes, libros, documentales y películas y, seguramente, su labor figuraría en los libros de Historia. Pero, lamentablemente, es española y en nuestro país tenemos la manía de creernos lo malo que se dice de nosotros y evitar sentirnos orgullosos de todo aquello que nos honra como pueblo. Pocas personas conocen que en contra de lo que sucedió en América del norte donde se llegó a infectar de viruela las mantas que habían de ser entregadas a los indígenas, un monarca hispano poco tiempo antes, costeó la primera misión humanitaria conocida para erradicar tan terrible mal.

Isabel es por tanto una mujer sobre la que es imprescindible insistir para que su nombre, como el de otras heroínas, salte a la memoria colectiva y sea recordada en la magnitud de su entrega personal y su dedicación al cuidado. Un cuidado silencioso y continuo que han realizado con entrega especial muchas mujeres y todas de forma generalizada, sin los cuales la vida de que disfrutamos en la actualidad no hubiese sido posible. Descubrir la aventura de la Real Expedición e imaginar a una Isabel llena de fuerza y de carácter es lo que pretende la obra "La aventura ultramarina de 
Isabel Sendales". Una mujer vitalista, capaz de abrazar la vida de frente, sin miedos, o superando los que se le iban presentado, sin gazmoñería ni sentimentalismos.

\section{RefERENCIAS Bibliográficas}

AA. VV., Gómez Ulla. Hospital Militar Central. Cien Años de Historia, Ministerio de Defensa, Madrid, 1996.

AA. VV., “La Ciencia Antigua y Medieval (de los orígenes a 1450)”, Historia General de las Ciencias, Vol. I, dir. René Taton, Destino, Barcelona, 1985.

AA. VV., Las Hijas de la Caridad en los Hospitales Militares, Madrid, (edición impresa, sin editar conservada en el Archivo de la Casa Provincial de las Hijas de la Caridad en Madrid), 4 Vols., 2004.

AA. VV., Luisa de Marillac, Editorial CEME, Santa Marta del Tormes, 1991.

AA.VV., Recuerdos de Carabanchel. Historia y cultura, edic. la Librería, Ayuntamiento de Madrid, 2003

AA. VV., Vicente de Paúl y los enfermos, Editorial CEME, Santa Marta del Tormes, 1978. Aimar, A., Videla, N. y Torre, M., "Tendencias y perspectivas de la ciencia enfermera", Enfermería Global, no 9, noviembre 2006, pp. 1-9.

Álvarez Ricart, Mํ del C., La mujer como profesional de la medicina en la España del siglo XIX, Anthropos, 1988, Barcelona.

Arenal, C., La beneficencia, la filantropía y la caridad, Imprenta del Colegio de sordomudos y ciegos, Madrid, 1861

Arias Bautista, M. T., "Catalina de Siena", Las sabias mujeres II (Siglos III-XVI). Homenaje a Lola Luna, Asociación Cultural Al-Mudayna, Madrid, 1995, pp. 103-125.

----, “Hildegarda de Bingen”, Historia 16, año XXI, no, 243, Madrid, julio 1996, pp. 99-108.

---, Violencias y mujeres en la Edad Media Castellana, Castellum, Madrid, 2007.

----, "Frontera de sí, frontera de Dios. El cuerpo femenino en la Edad Media", De lo sagrado y lo profano. Mujeres tras/entre/sin fronteras, Arcibel Editores, Sevilla, 2009, pp. 31-54.

Badinter, E., L'un est l'autre, Odile Jacob, 1986.

Balfour, S., "Nuevas y viejas interpretaciones del 98 y de sus consecuencias en España", XIII Coloquio de Historia Canario-Americana, VIII Congreso Internacional de Historia de América, 1998, Las Palmas de Gran Canaria, 2000, pp. 35-42.

Bourdieu, P., La dominación masculina, Anagrama, Barcelona, 2000

Bruyne, E. de, La estética de la Edad Media, Visor, Madrid, 1987.

Caballero Navas, C. “Magia: experiencia femenina y práctica de la relación”, De dos en dos. Las prácticas de creación y recreación de la vida y la convivencia humana, Horas y horas, Madrid, 2000.
Cabanes Jiménez, P. "La medicina en la Historia Medieval Cristiana", Espéculo. Revista de estudios literarios, núm. 32, Universidad Complutense de Madrid, 2006.

Cabré i Paret, M., "Nacer en relación”, De dos en dos. Las prácticas de creación y recreación de la vida y la convivencia humana, Horas y horas, Madrid, 2000, pp. 15-32.

Capel Martínez, Mํ R., El trabajo y la educación de la mujer en España (1900-1930), Ministerio de Cultura, Madrid, 1986

Capilla Pérez, A., “Concepción Arenal: Un enfoque desde el trabajo social”, Portularia 1, 2001, Universidad de Huelva, 155-170.

Carrillero Millán, A. M., “El trabajo de las mujeres en las unidades domésticas campesinas del sureste peninsular durante el Alto Imperio romano", Mujeres y Arqueología. Nuevas aportaciones desde el materialismo histórico. Homenaje al prof. Manuel Carrillero Millán, Junta de Andalucía, Granada, 2008

Castellanos, P. L., "Sobre el concepto de salud-enfermedad. Un punto de vista epistemológico", Revista Facultad Nacional de Salud Pública, Universidad de Antioquia, vol. 11, ene-jun 1988, pp. 40-55.

Castañega, M., Tratado de las supersticiones y hechicerías y de la possibilidad y remedio dellas (1529), Edic. Juan Robert Muro Abad, Instituto de Estudios Riojanos, Logroño, 1994.

Ciudad Jiménez, A., El Hospital de Maudes. La adaptación de un edificio a través de la Historia Consejería de Obras Públicas, Urbanismo y Transporte, CAM, 2001.

Delicado, F., La lozana andaluza, Edic. Bruno Damián, Clásicos Castalia, Madrid, 1969.

Disposiciones Oficiales Vigentes acerca de las Hijas de la Caridad en los Hospitales Militares, Imp. Vallinas, Madrid, 1923.

“Documentos Fundacionales de las Huelgas” en Cistercium, 173, (1987).

Echevarri Chavarri, C., “Hospitalidad-Enfermería, conceptos unívocos”, Cultura de los cuidados, 2o semestre 2006, año X, no 20, pp. 32-38

El sacrosanto y Ecuménico Concilio de Trento, traduc. de Ignacio López de Ayala, $7^{\mathfrak{a}}$ edic., Imprenta Sierra y Martí, Barcelona, 1828.

Escribano, E., Las Hijas de la Caridad de la Provincia Española. Trescientos veinticinco hospitales de Sangre durante la cruzada nacional, 3 vols., Gráficas Uguina, Madrid, 1942.

Ferragud Domingo, C., “La atención médica doméstica practicada por mujeres en la Valencia bajomedieval", Dynamis, 2007.

Flinton, M., Santa Luisa de Marillac. El aspecto social de su obra, Editorial CEME, Salamanca, 1974 Gallent Maraco, M., "Problemas fundamentales en torno a la historia de la Sanidad Medieval en la Península Ibérica", IV Semana de Estudios Medievales del 2 al 6 de agosto de 1993, Nájera, 1994, pp. 189-206. 
Garrido González, E., "una igualdad inicial" en Historia de las mujeres en España, Editorial Síntesis, Madrid, 1997.

González y Valencia, I., Crónicas de Carabanchel Bajo, Madrid, 1891.

Goodman, D. y Navarros, V., Poder y penuria: Gobierno, tecnología y sociedad en la España de Felipe II, Alianza Editorial, Madrid, 1990

Granjel, L. S., “La medicina española del siglo XVIII”, Historia General de la Medicina Española, Vol. 4, Universidad de Salamanca, Salamanca, 1981-1986.

Graziosi, Marina, “En los orígenes del machismo jurídico. La idea de inferioridad de la mujer en la obra de Farinacio", Jueces para la democracia, núm. 30 (1997), pp. 49-56.

Green, M., “En busca de una auténtica medicina de mujeres: los extraños destinos de Trota de Salerno e Hildegarda de Bingen", Sanadoras, matronas y médicas en Europa, siglos XII-XX, Icaria, Barcelona, 2001, pp. 9-27.

Guillamón Álvarez,F.J., “Disposiciones sobre policía de pobres:establecimiento de diputacione de barrio en el reinado de Carlos III", Cuadernos de Historia Moderna y Contemporánea, $\mathrm{n}^{\mathrm{o}} 1$ 1980, pp. 31-50.

Hellwarth, J., “Lady Grace Milmay, una Sanadora inglesa del siglo XVI”, Sanadoras, matronas y médicas en Europa, siglos XII-XX, Icaria, Barcelona, 2001, pp.93-114.

Hernández Iglesias, Fermín, La beneficencia en España, Establecimiento Tipográfico de Manue Minuesa, Madrid, 1876

Hernández Martín, Francisca, “Las Hijas de la Caridad en la profesionalización de la enfermería", Cultura de los Cuidados, 2os semestre 2006, año X, nº 20, pp. 39-49.

Iglesias Aparicio, P., Las pioneras de la medicina en Gran Bretaña, tesis doctoral, Edición digital, Universidad de Vigo, 2003.

Kay Martin, M. y Voorhies, B., La mujer: Un enfoque antropológico, Anagrama, Barcelona, 1978.

Klairmont-Lingo, Alison, "Las mujeres en el mercado Sanitario de Lyon en el siglo XVI", Sanadoras, matronas y médicas en Europa, siglos XII-XX, Icaria, Barcelona, 2001, pp. 77-92.

Lefebvre, G., y Porce, J. F., “La medicina egipcia”, La ciencia antigua y medieval. De los orígenes a 1450, Vol. I, Ediciones Destino, Barcelona, 1985

López-Cordón Cortezo, Mํㅡ. V., “La situación de la mujer a finales del Antiguo Régimen (17601860)", Mujer y sociedad en España (1700-1975), Ministerio de Cultura, Madrid, 1986

López de la Cruz, L., "La presencia de la mujer en la Universidad Española”, Revista Historia de la Educación Latinoamericana, Universidad Pedagógica y Tecnológica de Colombia, $\mathrm{n}^{\mathrm{o}} 4$ (2002), pp. 291-299.

López Montesinos, Mํㅗ. “Revisión cronológica de la enseñanza de enfermería en España”, Enfermería Global, Universidad de Murcia, ํo 5, noviembre 2004, pp. 1-6.
Madero Eguía, M., Manos violentas, palabras vedadas. La injuria en Castilla y León (siglos XIII-XV), Taurus, Madrid, 1992.

Maloney, R. P., Cinco Rostros de Rosalía Rendu, conferencia impartida en la Casa Madre de París, el 25 de marzo de 2003.

Manual de las Hijas de la Caridad sirvientas de los pobres enfermos en el Hospital y en la visita domicilio, ed. La Milagrosa, Madrid, 1952.

Martínez de Toledo, A., Corbacho, Edic. Michael Gerli, Cátedra, Madrid, 1979.

Médicos y Medicina en la Antigüedad Clásica. Antología de textos, edic. de Eduardo Acosta Méndez, Fundación Canaria Hospitales del Cabildo de Tenerife, 1999.

Menéndez Pidal, R., Tres Poetas primitivos, Espasa Calpe, Madrid, 1968.

Morente Parra, M ${ }^{\mathrm{a}}$ I., “La Virgen como cuidadora y Sanadora a través de las Cantigas de Santa María de Alfonso X", Hiades. Revista de Historia de la Enfermería, núm. 8, 2001, pp. 337-341.

Muraro, L., “I cavalieri delle donne”, Via Dogano. Rivista di Politica 21/22 , 1995.

Nieto, P., Historia de las Hijas de la Caridad, Biblioteca San Vicente de Paúl, Imprenta Regina, Madrid, 1932, 2 vols.

Noah Kramer, S., La Historia empieza en Sumer, Biblioteca de la Historia, Ediciones Orbis, Barcelona, 1985.

Opitz, C., "Vida cotidiana de las mujeres en la Baja Edad Media (1250-1500)", Historia de las mujeres. La Edad Media, Vol. 2, Taurus, Madrid, 1992, pp. 321-399.

Parentini, M ‥, Historia de la enfermería. Aspectos relevantes desde sus orígenes hasta el siglo XX, Edic. Trilce, Montevideo, 2002.

Pejenaute Rubio, F., “El prólogo de Venancio Fortunato a la Vida de Santa Radegunda frente a los de Baudonivia y Hildeberto de Lavardin”, Minerva. Revista de Filología Clásica, 18 (2005) , pp. 171-186.

Pérez de Tudela y Velasco, M. ${ }^{a}$ I., “El espejo Mariano de la feminidad en la Edad Media Española", Anuario Filosófico, 1993 (26), pp. 621-634.

Pomata, G., "Entre el cielo y la tierra: las Sanadoras de Bolonia en el siglo XVI", Sanadoras, matronas y médicas en Europa, siglos XII-XX, Icaria, Barcelona, 2001, pp. 115-142.

Pulgar, H. del, "Crónica de los Señores Reyes Católicos Don Fernando y Doña Isabel de Castilla y Aragón, escrita por su cronista...", Crónicas de los Reyes de Castilla, desde Alfonso el Sabio hasta los Católicos Don Fernando y Doña Isabel, Edic. Cayetano Rosell, Biblioteca de Autores Españoles, Tomo I, Atlas, Madrid, 1953.

Querol, Mª Á., De los primeros seres humanos, Ed. Síntesis, Madrid, 1991.

Ramírez Martín, S. M. y Tuells, J., “Doña Isabel, la enfermera de la Real Expedición Filantrópica de la Vacuna", Vacunas, 2007; 8 (3):160-6. 
Reder Gadow, M., "Las voces silenciosas de los claustros de clausura”, Cuadernos de Historia Moderna, 25, 2000, pp. 279-335.

Régimen y Servicio de las Hijas de la Caridad en los Hospitales Militares, Colección Legislativa del Ejército, no 185 , pp. 271-281.

Rodríguez, M del C., H. C, “Luisa de Marillac, pionera de unos servicios públicos y humanizadores", Luisa de Marillac, CEME, 1991.

Rojas Buendía, Mª del M., Los derechos fundamentales de libertad de conciencia y asociación: análisis histórico y régimen jurídico conjunto, tesis doctoral, edición digital, Universidad Carlos III de Madrid, 2006.

Ruiz de la Peña Solar, J. I., “Dos fundaciones hospitalarias medievales en el itinerario asturgaláico del Camino de Santiago: Fonfría y Montouto", Boletín del Real Instituto de Estudios asturianos, año no 48 , núm. 144, 1994, pp. 581-592.

Santa Luisa de Marillac. Correspondencia y escritos, Editorial CEME, Salamanca, 1985.

“Santa Luisa de Marillac y las primeras religiosas hospitalarias”, Ecos de la Casa Madre, nº 3, marzo 1974

Sánchez Suárez, Mํa Ángeles, Mujeres en Melilla, SATE-STEs y Grupo Editorial Universitario, Melilla, 2004.

Sanllorente, A. y López, V., Trinidad, Las Hijas de la Caridad en el Hospital Militar Gómez Ulla (1896-1988), (edición impresa, sin editar, conservada en la Casa de la Hijas de la Caridad del Hospital Gómez Ulla), Madrid, 1988.

Santo Tomás Pérez, M., “Analizar el pasado para proyectarse hacia el futuro", Hiades. Revista de Historia de la Enfermería, no 7, Septiembre, 2000.

Segura Graiño, C., "La sociedad feudal”, Historia de las mujeres en España, Síntesis, Madrid, 1997, pp. 153-184.

Soubeyroux, J., "Pauperismo y relaciones sociales en el Madrid del siglo XVIII". Estudios de Historia Social, 12 y 13, 1980, pp. 7-227.

Soldevilla, J. y Martínez, F., “Pasado y presente en el cuidado de las heridas”, Hiades. Revista de Historia de la Enfermería, 8, octubre 2001, pp. 469-477.

Torres Sánchez, C., La clausura femenina en la Salamanca del siglo XVII. Dominicas y Carmelitas Descalzas, Universidad de Salamanca, 1991.

Tuñón de Lara, M. “Los últimos días de un Imperio", en El desastre del 98, Cuadernos de Historia 16, nº 30, Madrid, 1985, pp. 6-16.

Trueba Mira, V., El claroscuro de las luces. Escritoras de la Ilustración española, Montesinos, Barcelona, 2005.
Valdeón Baruque, J., “El ritmo del individuo: en las puertas de la pobreza, de la vejez, de la enfermedad y de la muerte", La vida cotidiana en la Edad Media: VIII Semana de Estudios Medievales 4-8 de agosto de 1997, Nájera, 1998, pp. 275-288.

Valls Molind, R., Diseño de programas para la formación ética de los profesionales de la enfermería Tesis doctoral, edición digital, Universidad de Barcelona, 1993.

Vargas, P., Historia de las Hijas de la Caridad de la Provincia Española, Madrid, 1996

Vidal Galache, F., "El impacto de la Ley General de Beneficencia de 1822 en Madrid”, Revista de la Facultad de Geografía e Historia, núm. 1, 1987, pp. 41-56.

Vidal Galache, B., “Testamentos de civiles y militares fallecidos en instituciones de caridad en los siglos XVIII y XIX", Espacio, tiempo y forma. Serie V, Historia Contemporánea, nº 4, 1991, pp. 203-214.

Vidal Galache, F. y Vidal Galache, B., “Curar el cuerpo y salvar el alma. La asistencia en el Hospital General y Pasión (1767-1850)", Espacio, Tiempo y Forma, Serie V, H. ․ Contemporánea, T. 8, 1995, pp. 33-45.

Vives, J. L., Tratado del Socorro de los pobres, edición traducida por Juan de Gonzalo Nieto Ivarra Imprenta de Benito Monfort, Valencia, 1781, edición facsímil conmemorativa de los 100 años de Seguridad Social, Ministerio e Trabajo y Asuntos Sociales, Madrid, 2000.

Wade Labarge, M., La mujer en la Edad Media, Nerea, Madrid, 1986.

Walker, K., Historia de la Medicina, traducción del Dr. Jacinto Corbella, Credsa, Barcelona, 1966.

\section{REFERENCIAS BIBLIOGRÁFICAS SOBRE ISABEL SENDALES Y LA REAL EXPE-}

\section{DICIÓN DE LA VACUNA}

Aceves Pastrana, P. y Morales Conde, A., “Conflictos y negociaciones en las expediciones de Balmis", en Estudios de Historia Novohispana, núm. 17, 1997, pp. 171-200.

Águila Zamora, C. Hedy Hermina, "Las Fiestas Populares en Santa Clara durante el siglo XVIII" en Boletín Cartacuba, nº 46, julio del 2003 y en Revista "Amanecer" no 62, Año XI, julio-agosto, 2005.

Alamán, L., Historia de México desde los primeros movimientos que prepararon su independencia en el año 1808 hasta la época presente, tomo I, México, Imprenta de J. M. Lara, 1849, 649 pp.

Alcalá y Mendiola, M. de, Descripción en Bosquejo de la Imperial Cesárea, Muy Noble y Muy Leal Ciudad de Puebla de los Ángeles, Introd. Ramón Sánchez Flores, Puebla, Junta de Mejoramiento Moral, Cívico y Material del Municipio de Puebla, 1992, 206 pp.

Arana Amurrio, José I., “Evolución de los saberes pediátricos en España desde el tratado de Jerónimo Soriano. Cuatro siglos de historia", XXIX Congreso Nacional ordinario de Pediatría de la A. E. P., Tenerife, 14-17 Junio 2000.

Archila, R., "La expedición de Balmis en Venezuela", en IV Congreso Panamericano de Historia de la Medicina, Tip. Vargas S.A., Caracas, 1969. 
Arenal, C., La beneficencia, la filantropía y la caridad, 1861, Biblioteca Virtual Miguel de Cervantes.

Arévalo Ferro, C., “Teresa Herrera: La caridad hecha mujer", El Reportero, Revista digital, Coruña, 12 de abril de 2006.

Balaguer Perigüell, E. y Ballester Añón, R., La Real Expedición Filantrópica de la Vacuna (18031806), Monografías de la A.E.P, $\mathrm{n}^{\mathrm{o}} 2,197$ pp.

Barrantes, V. (1829-1898) “Historia de la piratería malayo-mahometana en Mindanao, Joló y Borneo" Boletín de la Real Academia de la Historia, tomo 20 (1892), pp. 155-159.

Barreiro Fernández, X. R., O liberalismo coruñés: a segunda xeración (1823-1846). Discurso lido na recepción pública do 14 de febreiro de 1997 por Xosé Ramón Barreiro Fernández e resposta de Don Xesús Alonso Montero. Real Academia Galega.

Benassar, B., Hernán Cortés. El conquistador de lo imposible, Trad. María Calonge. Temas de hoy. Madrid, 2002, 367 pp.

Bernabeu, "Salvador, Perlas para la reina. Aportaciones al estudio de la industria perlífera en la Nueva España (1790-1809)", Estudios de Historia Novohispana, núm.15, 1995, pp.129-158.

Bicentenario de la Real Expedición Filantrópica de la Vacuna, 1803 a 1806-2003 a 2006, Medicina Militar, Revista de Sanidad de las Fuerzas Armadas de España, vol. 60, nº 2, año 2004.

Blázquez Domínguez, C., “Grupos de poder en Xalapa en la 2ª mitad del siglo XVIII”, en ejournal, Universidad Nacional Autónoma de México, pp. 97-126.

Brigadier Diego, S., "Historias de la Vacunología", diciembre 2007 RM de A Coruña: tomo 2413, folio 84, hoja C-12502.

Brines Solanes, J., Manual del residente de pediatría y sus áreas específicas, Asociación Española de Pediatría, Capitel Editores, 1997, 1986 pp.

Castañeda de la Paz, M., "Presentación: Escuchar para oír", en Instituto de Investigaciones Antropológicas, UNAM, Anuario de Estudios Americanos, 65, 1, enero-junio, 13-20, Sevilla (España), 2008.

Decreto de Honores de Simón Bolívar, Bogotá, 12 de febrero de 1825, Colombia, Congreso, 2 folios, Biblioteca Nacional de Perú

Díaz de Ariola, G., La vuelta al mundo de la expedición de la vacuna (1803-1810), Facsímil de la edición de 1948, Biblioteca de Historia de América, Consejo Superior de Investigaciones Científicas, Madrid, 2003, 132 pp.

Díaz del Castillo, B., Historia verdadera de la conquista de Nueva España, Ed. Plaza Janés, España, 1998. 479 pp.

Diomedi, A. P. “La guerra biológica en la conquista del nuevo mundo. Una revisión histórica y sistemática de la literatura", en Revista Chilena de Infectología (2003); 20 (1): 19-25.

Domeyko, I., "Análisis de las Aguas minerales de Chile", en Anales de la Universidad de Chile, Tomo XVI, Febrero 1859, pp. 191 y ss.
Fernández Nieva, J., “Don Manuel Godoy: de Príncipe de la Paz a Príncipe Humanitario (Un aspecto peculiar de la vida cotidiana: el niño expósito. Visión y atención sanitarioeducativa. Materiales para la enseñanza)", Revista de Estudios Extremeños, Diputación de Badajoz, 3 (Septiembre-Diciembre), 2002, pp. 1115-1144.

Francisco Javier de Balmis, Archivo Museo Don Álvaro de Bazán, El Viso del Marqués, Sección Sanidad, Legajo 2898/15, 17 pp.

----, Archivo General Militar de Segovia, Sección Primera, Legajo B-341, 3 pp.

García Alcaraz, M. G., “La distinción entre educación pública y privada”, en La Tarea, Revista de Educación y Cultura del SNT-47, ํำ 16-17.

García Castañeda, S., “Moralidad y reformismo en las comedias del Marqués de Casa-Cajigal”, Biblioteca Virtual Miguel de Cervantes, Alicante, 2007.

----, "El ciego de Buenavista, un romancero de Eduardo Bustillo", Revista de Folklore, Caja España, Obra social, Fundación Joaquín Díaz, 1999, Tomo: 19b, no 223, pp. 3-8.

García Nieto, V., “En el Segundo Centenario de la Llegada de la Expedición Balmis a Canarias”, Boletín de la Sociedad Canaria de Pediatría, 2003; 27 -nº 3 pp. 325-327.

---- y Hernández, J., “La Real Expedición Filantrópica de la Vacuna en Canarias (9 de diciembre de 1803 -6 de enero de 1804)", Asclepio, Vol. LVII-2-2005 pp. 151-171.

Gariot, J. B., Traité des maladies de la bouche d'aprés l'etat actuel des connaissances en Médicine et en Chirurgie, Imprimerie de Baudouin, Paris, 1805, 355 pp.

Gwarreti Aillón, J., “Real Expedición Filantrópica de la vacuna antivariólica, El dr. José Salbany Lleopart en la Audiencia de Charcas, Moxos y Chiquitos", Archivos Bolivianos de Historia de la Medicina, Vol. I, no 1, mayo de 1995, pp. 15-18.

Garrido Asperó, M. J., “La Fiesta de la Conquista de la Ciudad de México durante la Guerra de Independencia", Estudios de Historia Moderna y Contemporánea de México, Marcela Terrazas y Basante (editora), Alfredo Ávila (editor asociado), México, Universidad Nacional Autónoma de México, Instituto de Investigaciones Históricas, v. 27, 2004, pp. 5-34.

Gómez, A., “Terapéutica científica en Colombia: siglo XIX”, en Infectio, 2006; 10 (2): 89-94.

Grajales, A., "Criaturas bien nacidas aunque mal habidas y bien habidas aunque mal nutridas" en Nuevo Mundo Mundos Nuevos (en línea), Coloquios 2008, URL: http://nuevomundo. revues.org/index28012.html.

Herrera Hermosilla, J. C., El sueño ilustrado. Biografía de Francisco Javier de Balmis, Editorial Paracelso, 2004, 357 pp.

Hirschberg, J., "La fundación de Puebla de los Ángeles. Mito y realidad", en Ángeles y constructores. Mitos y realidades en la historia colonial de Puebla (Siglos XVI-XVII), de Carlos Contreras Cruz y Miguel Ángel Cuenya (eds), BUAP, México, 2000. 
Ibarra, Antonio, “Conspiración, desobediencia social y marginalidad en la Nueva España: La Aventura de Juan de La Vara”, Historia Mexicana, Vol. XLVII, núm. 1, pp. 5-34, Universidad Nacional Autónoma de México.

Jáuregui, L. y Semo, E., “De caminos, mulas y barcos. Los transportes en el México colonial y en los primeros años de vida independiente", en Los transportes, siglos XVI al XX, Universidad Nacional Autónoma de México, UNAM, pp. 21-71.

Labastida, J., Humboldt, ciudadano universal, siglo XXI, México, 1999, 396 pp.

López Espinosa, J. A., “Introducción de la vacuna contra la viruela en Cuba”, ACIMED, Febrero 10 de 1804.

Lozano Y Nathal, G., “La Feria de la Flota en Xalapa: 1720-1777”, México en el Tiempo, 25 de julio/agosto 1998

Marqués, J. N., “La vacuna en Cuba”, Infomed, portal de salud de Cuba, 10 de julio de 2004.

Mendoza Castillo, L. M. y Sánchez Morales, J., “Las revistas literarias del siglo XIX mexicano”, Educación de la mujer a través del sitio www.coleccionesmexicanas.unam.mx

Milton Rizzi, “Bicentenario de la expedición de la vacuna antivariólica y su introducción en el Río de la Plata", Revista Médica de Uruguay, vol. 23, núm.1, Montevideo, marzo 2000.

Moncada Maya, J. O., “La Ciudad de México a finales del siglo XVIII. Una descripción por el ingeniero Miguel Constanzó", Revista Bibliográfica de Geografía y Ciencias Sociales, (Serie Documental de Geo-Crítica), Instituto de Geografía de la Universidad Nacional Autónoma de México, Universidad de Barcelona, Vol. XI, nº 692, 10 de diciembre de 2006.

Muñoz Echabeguren, F., "Alza: El Trienio Liberal y la Invasión Francesa 1820-1828” Altza hautsa kenduz IX, 3, 2007, pp. 37-46.

Navarro García, L., "Los intendentes de Guadalajara en Nueva España”, Biblioteca Jurídica Virtual del Instituto de Investigaciones Jurídicas de la UNAM, www.juridicas.unam.mx., 593609 .

Nieto Antúnez, P., La Rectora de la Casa de Expósitos de La Coruña, excepcional y olvidada enfermera en la expedición Balmis, Instituto José Cornide de Estudios Coruñeses. Editorial Venus. La Coruña, 1981, $24 \mathrm{pp}$

Núñez Freile, B. y Núñez Cifuentes, I., “La expedición de los niños héroes: 16 de julio de 1805 bicentenario de la llegada de la vacuna de la viruela a la Real Audiencia de Quito", Revista Médica Cambios, Vol. IV, nº 7, enero-junio 2005, pp. 15-24

Parrilla Hermida, M., "La Expedición Filantrópica de la Vacuna Antivariólica a América en 1803. El contrato de fletamento de la corbeta María Pita", pp. 203-209.

Pedro del Barco, Archivo Museo Don Álvaro de Bazán, El Viso del Marqués, Sección Sanidad, Legajo 2898/16, 9 pp.

----, Archivo Museo Don Álvaro de Bazán, El Viso del Marqués, Sección Reales Órdenes, Legajo 5983,4 pp.
----, Archivo Museo Don Alvaro de Bazán, El Viso del Marqués, Sección Cuerpo General, Legajo 6207114, 38 pp.

----, Archivo Museo Don Álvaro de Bazán, El Viso del Marqués, Reales Órdenes Ferrol, Legajo 5988, 4 pp.

Peña Espinosa, J. J., “Consumo de embriagantes en la Puebla del siglo XVIII", Relaciones, primavera, año/volumen XXV, núm. 98, Colegio de Michoacán, Zamora, México, pp. 237276.

Pérez Moreda, V., “La infancia abandonada en España (ss. XVI-XX)”, Discurso de ingreso en la Real Academia de la Historia (8-5-2005), Separata no 14, Mensajeros de la Paz, Madrid, 2005

Pérez Roque, E., "Xalapa de 1830 a 2007", La Valquiria, Diario de Xalapa, suplemento cultural 25 de noviembre de 2007

Ramírez Martín, Susana, “El Legado de la Real Expedición Filantrópica de la Vacuna (18031810): Las Juntas de Vacuna", Asclepio, Vol. LVI-1-2004, pp. 33-61.

----, La salud del Imperio. La Real Expedición Filantrópica de la Vacuna, Fundación Jorge Juan, Madrid, 2002, 262 pp.

---- y Tuells, José, “Doña Isabel, la enfermera de la Real Expedición Filantrópica de la Vacuna", Vacunas, 2007; 8 (3): 160-6.

----, “Única mujer participante en la Real Expedición Filantrópica de la Vacuna. Doña Isabel Sendales y Gómez", Actas del IX Congreso Internacional de Historia de América, Vol. II, Edic. Regional de Extremadura, 2002, pp. 271-276.

----, “El niño y la vacuna de la viruela rumbo a América: La Real Expedición filantrópica de la Vacuna (1803-1806)", Revista Complutense de Historia de América, 2003, 29, 77-101.

Riera Blanco, M., y Rigau-Pérez, J. G., “Los Primitivos de la Vacuna en Tarragona y el Ingeniero de Marina Don Juan Smith”, Gimbernat: revista catalana d'història de la medicina i de la Ciència 1992, Vol. 17, pp. 289-303.

Rodríguez Gallardo, A., "Notas para el estudio del azogue en México en el siglo XVII" en Estudios de Historia Novohispana, Vol. 8, pp. 223 -242.

Ruiz Abreu, C., "Plagas, epidemias y muertes en el puerto de Villahermosa, siglo XVIII", pp. 141-149 en Tabasco: antiguas letras, nuevas voces", VI Congreso Internacional de Mayistas celebrado en Villahermosa, Julio 2004, edic. Mario Humberto Ruz, Universidad Nacional Autónoma de México, Mérida, 2005, 202 pp.

Salazar Andreu, J. P., "Algunos aspectos políticos y Jurídicos del Obispo de Puebla Salvador Biempica y Sotomayor (1790-1802)", Revista Jurídica, Anuario Mexicano de Historia del Derecho, Biblioteca Jurídica Virtual UNAM.

Sefchovich, S., La suerte de la consorte. Las esposas de los gobernantes de México: Historia de un olvido y relato de un fracaso, Océano, México, 1999. 
Simón Palmer, Ma del C., "La mujer y la literatura en la España del siglo XIX”, AIH, Actas VIII, 1983, pp. 591-597.

Suárez Fernández, L., Historia general de España y América: 711-1085 Tomo 4. La España de los cinco reinos: 1085-1369, Tomo 5. Los Trastámara y la unidad española: 1369-1517, Tomo. 6. La Época de plenitud: hasta la muerte de Felipe II, 1517-1598, Tomo 7. El Descubrimiento y la fundación de los reinos ultramarinos: hasta...Ediciones Rialp, 1981, 631 pp.

Tanck de Estrada, D. La Ilustración y la educación en la Nueva España (1731-1787), Ediciones el Caballito, México, 1985, 195 pp.

Teniente General Marqués de Casa Cajigal, Archivo General Militar de Segovia, Sección Primera, Legajo c-292, 6 pp.

Todo a babor. Revista divulgativa de historia naval en Internet, www.todoababor.es

Tuells, J. y Ramírez, S., Balmis et variola, SM Ed. Generalitat Valenciana, 2003, 278 pp.

Tuells, J., "Balmis, un pionero de la vacunación global", El autoclave, Revista del Club Español de Esterilización, Área de Salud Pública, Consejería de Sanidad de la Comunidad Valenciana, año 15, núm. 1, abril 2003, pp. 38-44.

Uriol Salcedo, J., “Un museo en Nuevo México (EE. UU.) para un camino español del siglo XVI", en Historia y Cultura de la Ingeniería Civil, Revista de Obras Públicas, diciembre 2003, núm. 3459, pp. 51-53.

Veiga de Cabo, J., Fuente Díez, E. de la y Martín Rodero, H., “La Real Expedición Filantrópica de la Vacuna (1803-1810)", Med. Segur. Trab., 2007, Vol. 53, no 209, pp. 71-84. 